(c) ACM, 2007. This is the author's version of the work. It is posted here by permission of ACM for your personal use. Not for redistribution. The definitive version was published in: Lourdes Moreno, Paloma Martínez, Belén Ruíz, and Ana Iglesias. 2007. Accessible interface for multimedia presentation in inclusive education. In Proceedings of the 12th annual SIGCSE conference on Innovation and technology in computer science education (ITiCSE '07). ACM, New York, NY, USA, 321-321. DOI=10.1145/1268784.1268888 http://doi.acm.org/10.1145/1268784.1268888

The definitive version was also published in: Lourdes Moreno, Paloma Martínez, Belén Ruíz, and Ana Iglesias. 2007. Accessible interface for multimedia presentation in inclusive education. SIGCSE Bull. 39, 3 (June 2007), 321-321. DOI=10.1145/1269900.1268888; http://doi.acm.org/10.1145/1269900.1268888 


\section{Accessible Interface for Multimedia Presentation in Inclusive Education}

\author{
Lourdes Moreno \\ Computer Science \\ Department, Universidad \\ Carlos III de Madrid \\ Av. Universidad 30 - 28911 \\ Madrid, Spain \\ Imoreno@inf.uc3m.es
}

\author{
Paloma Martínez \\ Computer Science \\ Department, Universidad \\ Carlos III de Madrid \\ Av. Universidad 30 - 28911 \\ Madrid, Spain \\ pmf@inf.uc3m.es
}

\author{
Belen Ruíz \\ Computer Science \\ Department, Universidad \\ Carlos III de Madrid \\ Av. Universidad 30 - 28911 \\ Madrid, Spain \\ bruiz@inf.uc3m.es
}

\author{
Ana Iglesias \\ Computer Science \\ Department, Universidad \\ Carlos III de Madrid \\ Av. Universidad 30 - 28911 \\ Madrid, Spain \\ aiglesia@inf.uc3m.es
}

\begin{abstract}
Among the technological solutions to achieve an inclusive education, the educative electronic acces sible resources providing content adaptability is an alternative which reduces discrimination. It also favors th e inclusion with right equalities which can be used by students re gardless of their s pecific need and use contexts. Following this line of adaptability of contents on the web, a practical cas e [1] has been launched: an accessible interface of a $\mathrm{m}$ ultimedia resource with caption and audio description that offers the user the control over the decision of which sound and/or visual alterna tives he wants to be introduced to. This resource has been designed with Universal Design criteria which are found in the Inclusive Design methodological framework.
\end{abstract}

\section{Categories and Subject Descriptors}

H.5.2 User Interfaces, H.5.1 Multimedia Information Systems.

\section{General Terms}

Experimentation, Human Factors, Standardization.

\section{Keywords}

Inclusion, accessibility, special needs, multimedia. Interface.

\section{PRACTICAL CASE. ACCESSIBLE INTERFACE WITH MULTIMEDIA CONTENTS}

The approach presented here is the use of tools in the education that provides adaptation to each $\mathrm{s}$ tudent according to the access and learning characteris tics that they pos sess. The multi-modal interaction makes possible the access to $\mathrm{m}$ ultimedia educational resources by stude nts with disabilities. A User Centered-Design has been followe $\mathrm{d}$ in design and development, i.e. the fram ework of Inclusive Design that considers all ty pes of users and special needs.

The resource was done for The Spanish Centre of Captioning and Audio description (CESy A) [1] that works towards the accessibility in audiovisual $\mathrm{m}$ edia using captioning and audio description services.
The origin of this work is an investigation study ing the best way to integrate a multimedia resource in Internet in an accessible way [2]. A m ultimedia content is accessible when a user can access that content, regardles $\mathrm{s}$ acces $\mathrm{s}$ characteris tics and context of use. It is indispensable to provide alternative sy nchronized contents (captions, audio descrip tion, etc.) WCAG 1.0, but it is important too to provide accessibility to the resource.

The interface allows the user to activate and/or deactivate the different sound and textual alternatives within the $\mathrm{m}$ ultimedia information. It has been developed by SMIL 2.0 and the reproduction of the $\mathrm{m}$ ultimedia content is associated to an external player which has permitted:

- To add hypermedia elements as sociated to events, that has provided adaptability and allowing the user to control the different means (audio description, caption, both or none) in order to emphasize that the characteristic of adaptability is interactive.

- To follow the philosophy of SMIL, as well as synchronizing $\mathrm{m}$ eans which $\mathrm{m}$ akes the multimedia content accessible, accessibility is provided allowing the access to the interface and its use by means of different acces s devices such as the mouse, keyboard and now voice synthesis.

We have worked on the trial task with real users of the interface to revise usability and accessibility aspects. W e have also obtained good results in the validation and some suggestion of users who this considering in a redesign.

\section{CONCLUSIONS}

Here is pres ented an acces sible interface im plemented with XML technologies, as SMIL, to reproduce $m$ ultimedia educational contents with a universal design which favours the inclusion, interactively offering personalization of the alternative contents such as caption and audio description.

\section{REFERENCES}

[1] The Spanish Centre of Captioning and Audio description (CESyA), http://www.cesya.es , 2005.

[2] Moreno L., Iglesias A., Martínez P., Accessibility of Multimedia Resources in Web, WEBIST 2007. Barcelona, España. Marzo 2007. 